\title{
ANALYSES OF MULTI-YEAR SYNTHETIC APERTURE RADAR IMAGERY OF DRY-FALLEN INTERTIDAL FLATS
}

\author{
M. Gade*, S. Melchionna, L. Kemme \\ Universität Hamburg, Institut für Meereskunde, Hamburg, Germany - \\ Martin.Gade@uni-hamburg.de
}

KEY WORDS: Synthetic Aperture Radar, intertidal flats, shellfish, oysters bivalve beds, polarization

\begin{abstract}
:
We analyzed a great deal of high-resolution Synthetic Aperture Radar (SAR) data of dry-fallen intertidal flats in the German Wadden Sea with respect to the imaging of sediments, macrophytes, and mussels. TerraSAR-X and Radarsat-2 images of five test areas along the German North Sea coast acquired between 2008 and 2013 form the basis for the present investigation and are used to demonstrate that pairs of SAR images, if combined through basic algebraic operations, can already provide useful indicators for morphological changes and for bivalve (oyster and mussel) beds. Depending on the type of sediment, but also on the water level and on environmental conditions (wind speed) exposed sediments may show up on SAR imagery as areas of enhanced, or reduced, radar backscattering. The (multi-temporal) analysis of series of such images allows for the detection of mussel beds, and our results show evidence that also single-acquisition, multi-polarization SAR imagery can be used for that purpose.
\end{abstract}

\section{INTRODUCTION}

Intertidal flats are coastal areas that fall dry once during each tidal cycle. In Europe large intertidal flats can be found on the Dutch, German, and Danish North Sea coasts, on the U.K. east and west coasts, and along the French Atlantic coast, but also at other places worldwide, e.g. in South Korea and northwest Africa. Adopting the Dutch name those areas are often referred to as Wadden Seas. Since 2009 the German Wadden Sea is a UNESCO World Natural Heritage, and according to national and international laws and regulations (European Commission $1992,2000,2008)$ a frequent surveillance of the entire area is mandatory.

Remote sensing techniques are ideally suited for the surveillance of areas that are difficult to access. In this respect, Synthetic Aperture Radar (SAR) sensors, because of their allweather capabilities and their independence of daylight, may be the first choice; however, the radar imaging of bare soils is rather complex, and the very processes responsible for the backscattering of microwaves from exposed intertidal flats are still subject to ongoing research. Van der Wal et al. (2005) showed that the surface roughness decreases with the amount of mud and increases with the median grain size. Consequently, Van der Wal and Herman (2007), who analyzed SAR images of intertidal flats on the Westerschelde, The Netherlands, found that the radar backscatter from sandy sediments exceeds that from muddy sediments, though water puddles with spatial coverages exceeding 50\% may decrease the effective surface roughness responsible for the radar backscattering (Kim et al. 2011).

Van der Wal and Herman (2007) were the first to combine optical and SAR data of dry-fallen intertidal flats on the Westerschelde. More recently, Dehouck et al. (2011) used TerraSAR-X data and optical imagery of the Arcachon Bay, France, to detect mussels, salt marshes, and sandy sediments. Similar to Gade et al. (2014), they showed that radar has great potential to complement optical sensors for the routine monitoring of intertidal flats.
Slatton et al. (2008) analyzed several L-band SAR images with respect to temporal changes in multi-polarization signatures of coastal wetlands. The use of polarimetric SAR data was also supported by Won (2009) and Lee et al. (2012), the former comparing polarimetric SAR signatures of salt-marsh plants on the South Korean coast with ground-based radar measurements, the latter finding that the radar backscatter from wetlands is stronger at horizontal $(\mathrm{HH})$ than at vertical (VV) polarization. In addition, Choe et al. (2012), demonstrated that polarimetric SAR data can also be used to detect mussel beds. Those bivalves, sticking out of the sediment, increase the surface roughness locally, and this is why they are visible on SAR imagery (Dehouck et al. 2011; Choe et al. 2012; Gade et al. 2014). Pacific oysters, rapidly spreading over large parts of the German Wadden Sea, can thus be monitored using spaceborne SAR sensors, even when they are working at different radar bands.

Within the German national project SAMOWatt ("Satellite Monitoring of the Wadden Sea", part of Phase II of the joint national project DeMarine), we have analyzed SAR images of dry-fallen intertidal flats on the German North Sea coast to gain further insight into mechanisms of the radar backscattering from those flats, and to provide a basis for the inclusion of SAR data into existing classification systems, which were built upon optical data (Brockmann and Stelzer 2008). Gade et al. (2014) already demonstrated that multi-frequency SAR imagery may be used to extract surface roughness parameters of dry-fallen intertidal flats. However, their inversion scheme requires Lband SAR imagery, which was no longer available after the sudden end of the ALOS-1 mission in 2011. Nonetheless, Gade et al. (2014) also showed that single-frequency, multi-temporal SAR imagery can be used for the detection of bivalve (oyster) beds. In the present paper we proceed along those lines and summarize some of our results obtained through the analysis of a great deal of SAR images acquired close to low tide over exposed intertidal flats on the German North Sea coast.

\footnotetext{
* Corresponding author
} 


\section{TEST SITES AND DATA}

Five test areas on the German North Sea coast were identified (Figure 1), which represent areas of typical sediment distributions on intertidal flats, but also include vegetated areas and mussel and oyster beds. Three of them, namely the test areas "Amrum", "Pellworm" and "Wesselburen" (denoted as "A", "P" and "W", respectively, in Figure 1) are located in the northern part of the German North Sea coast, in the German National Park "Schleswig-Holstein Wadden Sea". The other two test areas, "Norderney" and "Jadebusen" ("N" and "J", respectively, in Figure 1), are located further south and are part of the German National Park "Lower Saxonean Wadden Sea". Most of those test areas were already subject to previous studies (Gade et al. 2008, 2014), and they were complemented by the test area "Jadebusen", because this bay is characterized by a high spatial variability in surface types, along with strong tidal currents.

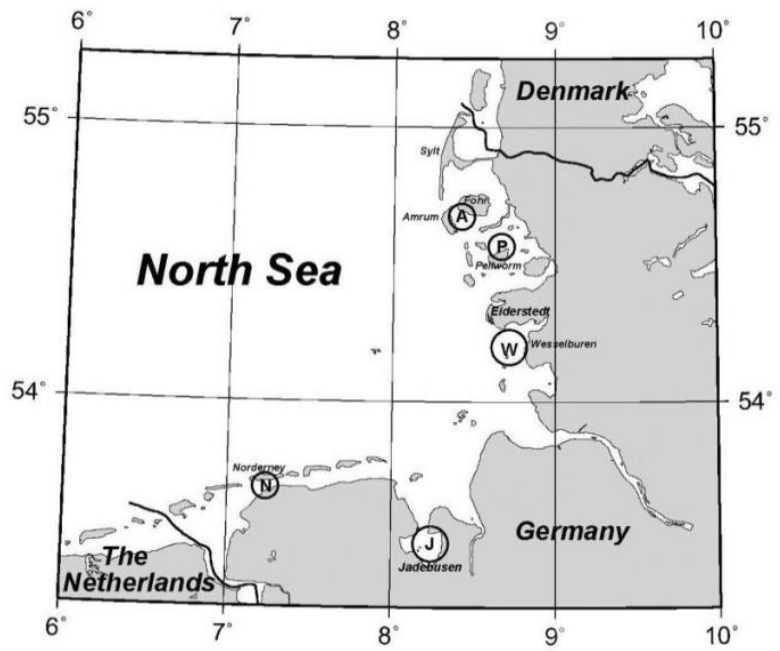

Figure 1. Five test sites on the German North Sea coast. A: "Amrum", P: "Pellworm", W: "Wesselburen", J: "Jadebusen" and N: "Norderney"

The test site "Amrum" is the northernmost test site, between the islands of Amrum and Föhr (Figure 1), and contains sandy and muddy sediments, bivalve beds (mainly oysters [crassostrea gigas] and cockles [Cerastoderma edule], but also blue mussels [mytilus edulis]), and seagrass meadows (of zostera noltii and zostera marina). Oysters have been invading into that area only recently: first observations of this species were made about thirty years ago, and a structurally relevant expansion started only in the first decade of the $21^{\text {st }}$ century (Diederich et al. 2005). Meanwhile most bivalve beds are dominated by oysters, whose size ranges from $5 \mathrm{~cm}$ to $30 \mathrm{~cm}$, while blue mussels are smaller than $7 \mathrm{~cm}$.

Together with the "Amrum" test site, "Pellworm" is part of an area called "Halligen Wadden Sea" including several small and undiked islands, called "Hallig", which are frequently flooded during storm surges. The "Pellworm" site lies north of the island of Pellworm (Figure 1) and has already been subject of previous studies focusing on the SAR imaging of remnants of historical land use (Gade and Kohlus, 2011). Here, the sediment is mainly sandy, though consisting of morphologically harder clay and peat. Muddy sediments are mainly found along the coast and mark calm hydrologic situations.
The test area "Wesselburen" was chosen, because it can be considered as mostly unvegetated, except for narrow elongated areas along the coast, which are covered by seagrass during the vegetation period. "Wesselburen" covers the intertidal range south of the Eiderstedt peninsula on the Schleswig Holsteinean North Sea coast, and it was already subject to earlier SAR imaging by the multi-frequency SIR-C/X-SAR in 1994 (Gade et al. 2008). "Wesselburen" covers a wide range of tidal channels and creeks, whose very form and location may undergo strong interannual changes after heavy storms and storm surges in fall and winter. The sediments are mainly sandy, and muddy areas with a high percentage of fine sand are found only at the narrow arms of the tidal creeks and along the coast.

The "Norderney" test site lies in the south-western part of the German North Sea coast and covers the intertidal range on the backside of the island of Norderney. The test site is dominated by a strong spatial variation in sediment types: the upper soil layer mainly consists of sandy sediments, but also muddy areas can be found in the eastern center of the site, at the watershed between two main tidal channels. The most prominent peculiarity of the "Norderney" test area, however, are extended areas in the site's center populated by seagrass (again, zostera noltii and zostera marina) and extended bivalve beds of blue mussels and Pacific oysters (Gade et al. 2014).

The "Jadebusen" test site has been recently included into our studies, because the Jade Bight is a semi-enclosed bay at the mouth of the (small) river Jade, including sandy and muddy sediments and extended bivalve beds and being subject to strong tidal currents. A deep tidal channel in the bay's center allows inflow and outflow of sea water from/to the open sea, while its arms reach into shallow areas along the coast, which are covered by seagrass during the vegetation period.

More than 120 SAR images of the SAMOWatt test areas, acquired between July 2008 and December 2013 by SAR sensors aboard the Canadian Radarsat-2 and the German TerraSAR-X and TanDEM-X satellites form the data basis of the analyses presented herein. Depending on the acquisition mode, the SAR systems provided imagery with pixel sizes ranging from $3 \mathrm{~m}$ down to $1 \mathrm{~m}$, or even below, thereby allowing for detailed studies of the radar backscattering from exposed intertidal flats. Some details of the used SAR images are given in Table 1.

\begin{tabular}{|l|c|c|c|c|}
\hline Satellite & $\begin{array}{c}\text { Freq. } \\
\text { (Band) }\end{array}$ & Pixel Size & Pol. & Amount \\
\hline & & $0.8 \mathrm{~m} \times 0.8 \mathrm{~m}$ & & 3 \\
Radarsat-2 & $5.41 \mathrm{GHz}$ & $1.0 \mathrm{~m} \times 1.0 \mathrm{~m}$ & $\mathrm{VV}$ & 13 \\
& $(\mathrm{C}$ Band) & $1.6 \mathrm{~m} \times 1.6 \mathrm{~m}$ & & 1 \\
& & $3.0 \mathrm{~m} \times 3.0 \mathrm{~m}$ & & 4 \\
\hline & & $0.5 \mathrm{~m} \times 0.5 \mathrm{~m}$ & $\mathrm{VV}$ & 22 \\
& & $0.75 \mathrm{~m} \times 0.75 \mathrm{~m}$ & & 10 \\
\cline { 3 - 5 } TerraSAR-X, & $9.65 \mathrm{GHz}$ & $1.25 \mathrm{~m} \times 1.25 \mathrm{~m}$ & & 6 \\
TanDEM-X & (X Band) & $1.0 \mathrm{~m} \times 1.0 \mathrm{~m}$ & $\mathrm{VV}$, & 36 \\
& & $1.5 \mathrm{~m} \times 1.5 \mathrm{~m}$ & $\mathrm{HH}$ & 26 \\
& & $2.5 \mathrm{~m} \times 2.5 \mathrm{~m}$ & & 8 \\
\hline
\end{tabular}

Table 1. SAR systems parameters and used SAR scenes

\section{RESULTS}

\subsection{Indicators for Shellfish (Bivalve) Beds}

3.1.1 Multi-temporal analyses: The large amount of SAR images allowed for thorough analyses of the temporal variability of the backscattered radar signal for each of the 
SAMOWatt test sites. Four TerraSAR-X images of the "Jadebusen" test site, which were acquired in summer and fall of 2012, are shown in Figure 3. In all panels an extended oyster bed in the north-eastern part of the bay (marked by a white arrow) caused a relatively high radar backscatter, i.e. it appears brighter than its surroundings. Because of their overall size and the great fraction sticking out of the sediment (or water, see Figure 2), and because of their heterogeneous orientation, oysters always cause an increase in radar backscatter. This effect, in turn, can be used to generate indicators for oyster beds through a statistical analysis of multi-temporal SAR imagery (Gade et al. 2014).

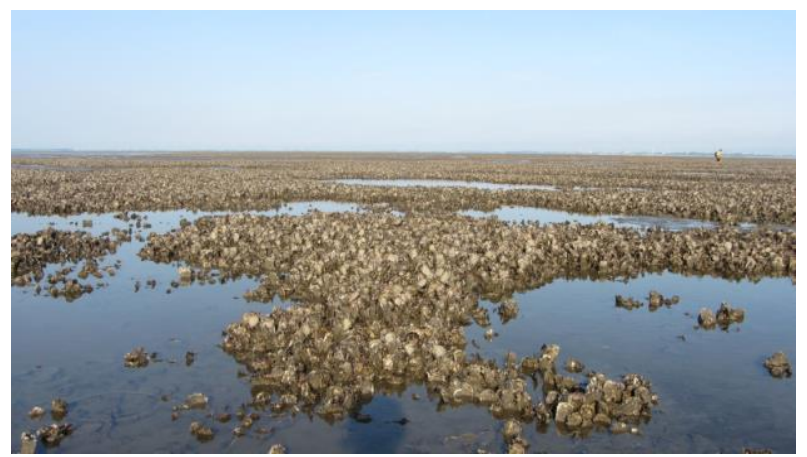

Figure 2. Extended oyster bed in the test site "Jadebusen" (photograph: S. Melchionna)

We used five TerraSAR-X images of the "Jadebusen" test site acquired in 2012 to derive basic statistical parameters. For every $(4 \mathrm{~m} \times 4 \mathrm{~m})$ pixel of the downscaled and collocated images we calculated the temporal mean value and standard deviation of the normalized radar cross section (NRCS). The upper panel of Figure 4 shows a false-color composite of the central $4400 \mathrm{~m} \times$ $2350 \mathrm{~m}$ part of the test site, with the green and magenta channels representing the mean and standard deviation, respectively.
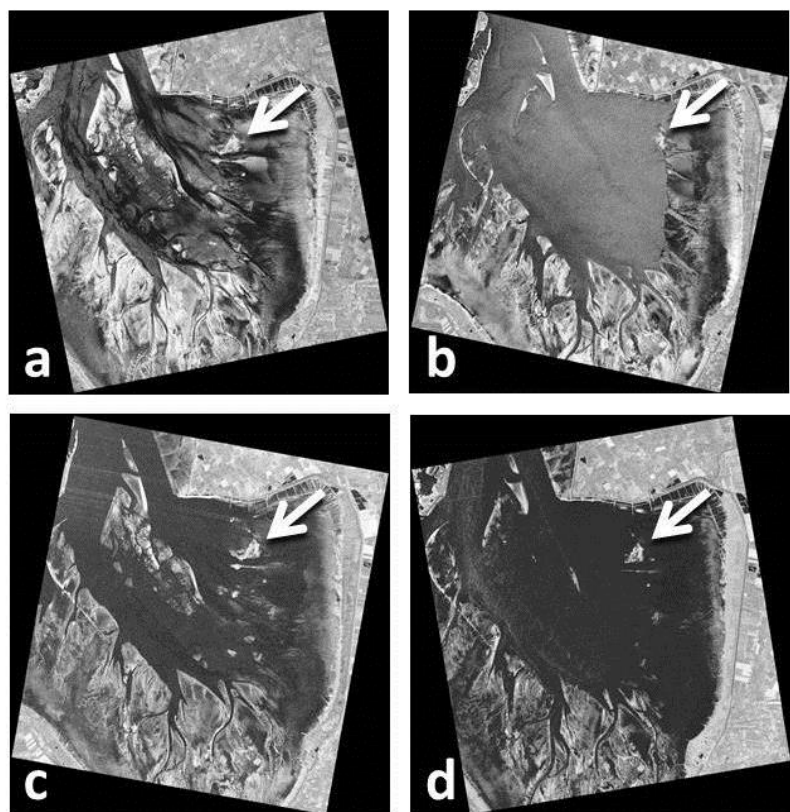

Figure 3. Test site "Jadebusen" imaged by TerraSAR-X in 2012: (a) July 3, 17:01 UTC (low tide at 17:26 UTC); (b) October 28, 05:51 UTC (04:36 UTC); (c) November 14, 05:42 UTC (05:35 UTC); (d) November 28, 17:10 UTC

(17:45 UTC). The white arrows mark an extended oyster bed, which appears always brighter than its surroundings
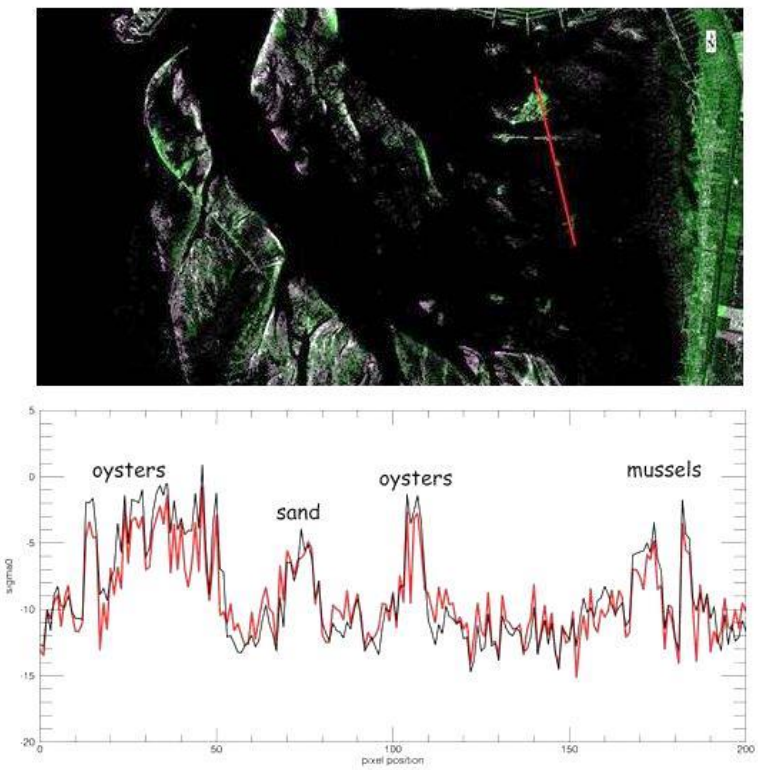

Figure 4. Temporal statistics for the test site "Jadebusen". Upper: false color composite of the mean value (green) and the standard deviation (magenta); lower: downward transect (red line in the upper panel); black: mean; red: standard deviation

Green areas, therefore, correspond to a large mean NRCS exceeding the standard deviation, and in magenta areas the standard deviation exceeds the mean NRCS. The lower panel shows the respective values along the red scan line inserted in the upper panel, with the mean marked in black and the standard deviation marked in red. Highlighted are areas of oyster and mussel beds and of sandy flats, which were identified during field campaigns.

Both the oyster/mussel beds and the sandy rim (the latter resulting from a former track used for the transport of cattle) cause high values of both the mean and standard deviation, see the local maxima in the lower panel of Figure 4. However, inside the bivalve beds the mean is exceeding the standard deviation, which is generally not the case in all other areas (including those with small values of mean and standard deviation, e.g. the dark areas in the upper panel of Figure 4).

Apparently, simple statistics can be used to infer mussel indicators, and consequently, similar results are already being used to improve an existing monitoring system based on optical data through the provision of improved estimates of the extent of the oyster bed in the "Norderney" test site (Gade et al. 2014).

3.1.2 Dual-polarization analyses: A large number of TerraSAR-X imagery was acquired at the two likepolarizations, $\mathrm{HH}$ and $\mathrm{VV}$, simultaneously, thereby allowing for investigations of the radar backscattering from intertidal flats at different polarizations. We define the polarization coefficient, $P C$, as the normalized difference polarization ratio:

$$
P C\left(S A R_{H H}, S A R_{V V}\right)=\frac{S A R_{H H}-S A R_{V V}}{S A R_{H H}+S A R_{V V}}
$$

where $S A R_{H H}$ and $S A R_{V V}$ are the respective (calibrated) SAR image data acquired by the same sensor and at the same time, but at horizontal $(\mathrm{HH})$ and vertical $(\mathrm{VV})$ polarizations. Two examples are shown in Figure 5, which were both derived from pairs of $\mathrm{HH}$ and $\mathrm{VV}$ polarization TSX images of the test site "Amrum" $(11.2 \mathrm{~km} \times 13.3 \mathrm{~km})$, acquired on June 6 (upper panel) and June 22 (lower panel), 2013. 


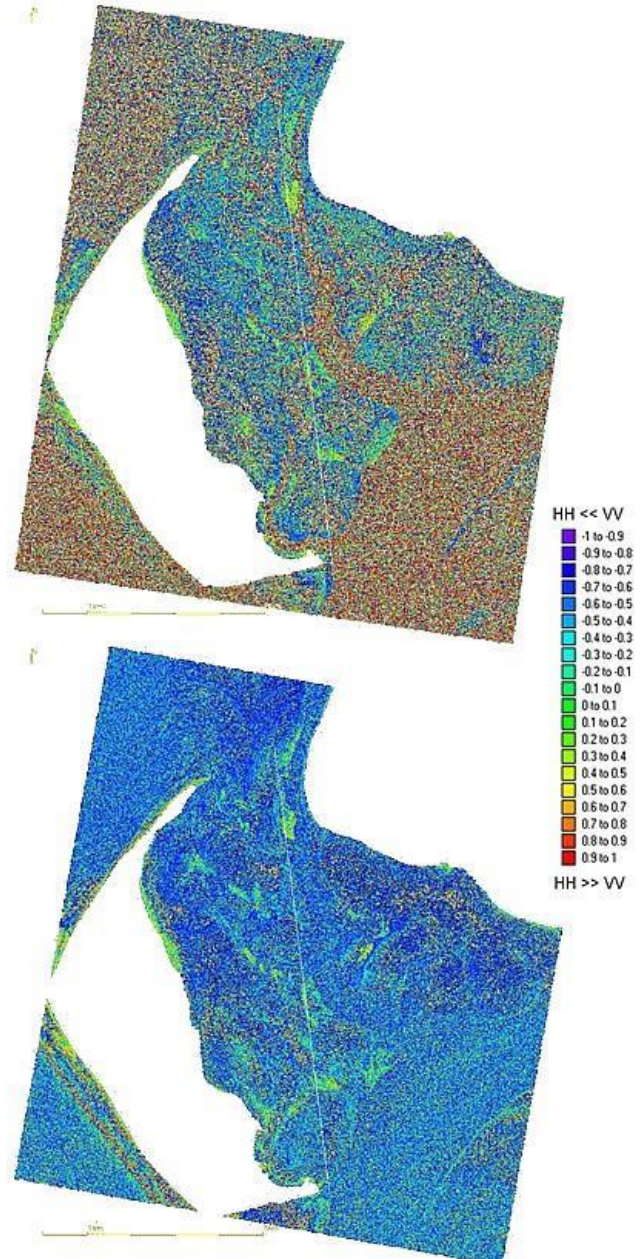

Figure 5. Polarization coefficient (normalized difference polarization ratio) calculated from dual-polarization TSX SAR images of the "Amrum" test site acquired on (upper) June 6 and (lower) June 22, 2013. Included as a vertical white line is the transect, along which the curves in Figure 6 were calculated

At the time of the first image acquisition (June 6; upper panel) the wind conditions were $4.3 \mathrm{~m} / \mathrm{s} / 26^{\circ}$ and during the second image acquisition (June 22; lower panel) they were $10.0 \mathrm{~m} / \mathrm{s} /$ $228^{\circ}$. Both islands, Amrum on the left and Föhr on the upper right, were masked out in both panels. Open flats appear in bluish (cyan to dark blue) colors, indicating higher backscatter at vertical polarization; however, several green patches with sharp edges can be seen on the open flats, between the two islands, and coincide with oyster beds monitored during recent field campaigns. The oysters, being arranged irregularly within the beds, with no dominant orientation, cause similar radar backscatter at both polarizations and, in turn, a polarization coefficient close to zero. Those patches are more pronounced, i.e. the contrast to their vicinity is much stronger, when the images were acquired at large incidence angles $\left(>40^{\circ}\right)$.

In order to quantify our results we have calculated along the vertical lines in Figure 5 the mean value of a moving window of length 11 (corresponding to approx. $17 \mathrm{~m}$ ), the respective standard deviation, and the absolute value of the product of both. The respective curves are shown in Figure 6, where the upper and lower panels correspond to the respective upper and lower panels in Figure 5. Locations of oyster beds, as identified during field campaigns in 2012, are marked with horizontal purple bars. In those areas the mean value (blue curve) always increases to values around 0 , and at the same time the standard deviation (red curve) decreases. These findings correspond to the observation of the smooth, greenish patches in in Figure 5, through which the transect is leading. As a result, the absolute value of the product of mean and standard deviation (green curve) drops to low values in those areas (Figure 6).

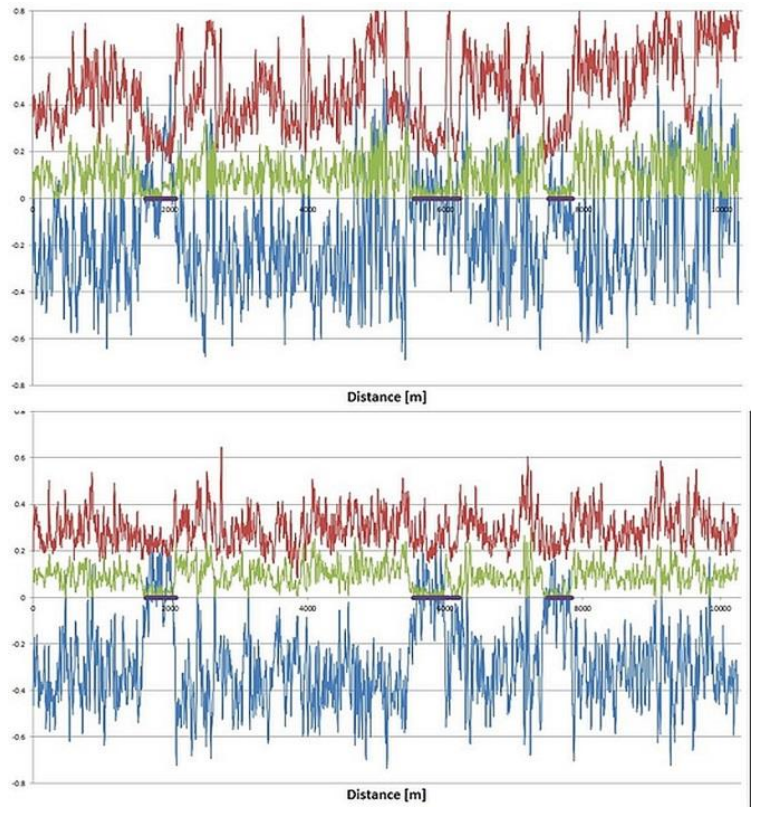

Figure 6. Transects along the white vertical lines in Figure 5; upper: June 6, lower: June 22, 2013. Blue curves correspond to the mean of a moving window of length 11, red curves to the respective standard deviation, and green curves to the absolute value of the product of both. Horizontal bars mark oyster beds

This parameter, derived through a chain of simple arithmetic operations, clearly helps deriving indicators for bivalve (oysters and mussel) beds: calculated for the entire imaged area (and performing the statistical operations for a moving twodimensional box) the resulting maps show local minima at those locations, which clearly coincide with locations of oyster beds detected during recent field campaigns (not shown herein). As an example, Figure 8 shows such a map, derived from the dualpolarization TerraSAR-X images of June 22, 2013.

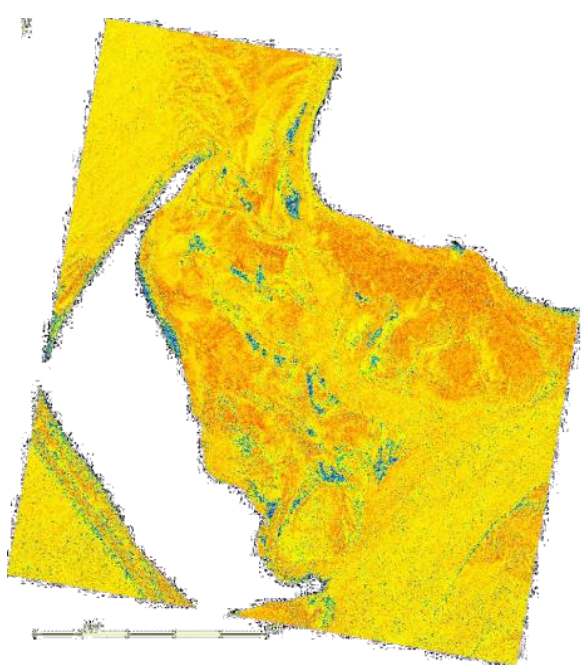

Figure 7. Result of the spatial computation of the new indicator for bivalve beds, derived as the absolute value of the local mean and standard deviation of the polarization coefficient (Eq. 1). Blue patches on the open flats correspond to areas with values below 0.02 and coincide with detected oyster beds. 


\subsection{Indicators for Morphodynamics}

The Wadden Sea is an area of high morphodynamics, and under the permanent action of currents and waves the location of the intertidal flats may change rapidly. As a consequence, highresolution SAR imagery of the same sensor (or, at least, acquired at the same radar band) may be used to investigate this change. Here, we are using two RS2 images of the test site "Wesselburen" acquired on October 17, 2009, at 16:56 UTC (14 minutes before low tide) and on September 5, 2013, at 17:08 UTC (50 minutes before low tide). During both image acquisitions, a moderate wind was reported in that area, thus making the two SAR images comparable with respect to the radar backscattering from a wind-roughened water surface. Similar to the polarization coefficient (Eq. 1) we define the temporal coefficient, $T C$, as the normalized difference temporal index of two SAR images acquired by the same sensor, but at different times:

$$
T C\left(S A R_{\text {new }}, S A R_{\text {old }}\right)=\frac{S A R_{\text {new }}-S A R_{\text {old }}}{S A R_{\text {new }}+S A R_{\text {old }}}
$$

where $S A R_{\text {new }}$ and $S A R_{\text {old }}$ are the respective younger and older, collocated (and calibrated) SAR images. Figure 8 and Figure 9 show temporal coefficients based on two RS2 images of October 2009 and September 2013. In order to pronounce the observed temporal changes we have overlaid on the older SAR image the areas with extreme temporal coefficients: red colors correspond to areas, where the NRCS in the newer SAR image is much (more than $10 \mathrm{~dB}$ ) higher, thus resulting in temporal coefficients exceeding $0.8(T C>0.8)$; blue colors correspond to the opposite, i.e. to areas, where the NRCS in the older SAR image is much higher and the temporal coefficient is below -0.8 $(T C<-0.8)$. Given that the observed differences are not only due to a different water level, the colored areas, therefore, mark regions of high morphodynamics (mainly in the outer, western parts of the test site), whereas relatively stable regions (closer to the coast and in the lower image center) appear in greyscales.

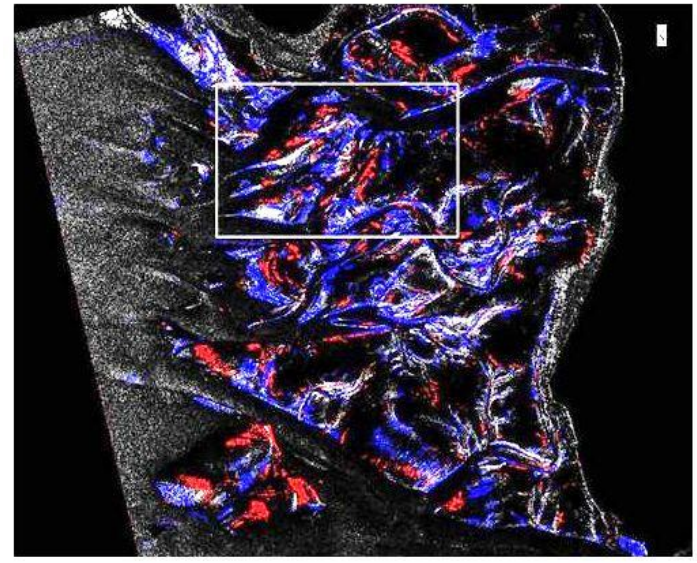

Figure 8. Temporal coefficient based on two Radarsat-2 SAR images of the test site "Wesselburen" acquired in October 2009 and in September 2013, shortly before low tide. Red colors mark areas of higher radar backscatter in the newer image $(T C>0.8)$; blue colors denote much higher radar backscatter in the older image $(T C<-0.8)$. The white rectangle corresponds to the image part shown in Figure 9

A closer look at the obtained results is provided in Figure 9, for the $(8 \mathrm{~km} \times 5 \mathrm{~km})$ area marked by the white rectangle in Figure 8. The upper two panels show the two RS2 SAR images (left: October 17, 2009, 16:56 UTC; right: September 5, 2013, 17:08 UTC) used for the calculation of the temporal coefficient in the lower panel. Again, only the values exceeding +0.8 and -0.8 are shown in red and blue colors, respectively). The lower panel shows that this is an area of high morphodynamics, i.e., an area where the tidal creeks are subject to frequent changes. We also note, however, that the water levels during both image acquisitions may have differed by about $10 \mathrm{~cm}$, which, per se, may cause differences in both SAR images, particularly at the edges of the tidal creeks.
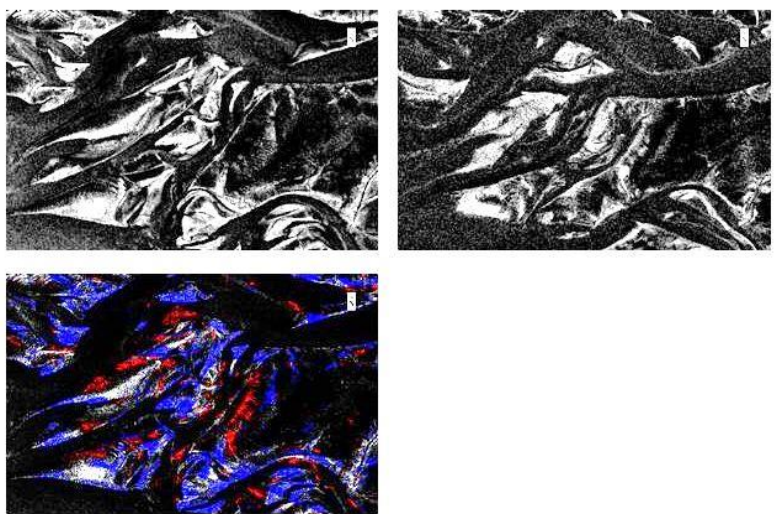

Figure 9. Subsections of the two SAR images used for the derivation of the temporal coefficient shown in Figure 8 (white rectangle). Upper left: Radarsat-2 SAR image of October 17, 2009; upper right: Radarsat-2 SAR image of September 5,

2013; lower: temporal coefficient, with the older SAR image underlying

Another example of SAR images used for multi-temporal analyses is shown in Figure 10: the test site "Pellworm" was imaged by TerraSAR-X on July 1, 2008, at 17:01 UTC (at low tide), on October 28, 2012, at 05:50 UTC (11 minutes after low tide), and on May 7, 2013, at 17:01 UTC (14 minutes before low tide). During all acquisitions, low wind speeds were reported, resulting in an overall low radar backscatter from the tidal channels and creeks (dark areas). During the 2008 and 2013 acquisitions (right panels in Figure 10) the wind was blowing from easterly directions, thus making those images most comparable, whereas the westerly wind during the 2012 acquisition may have resulted in a slightly higher water level. Nonetheless, the strongest differences can immediately be seen in the image centers, where a narrow tidal creek has changed its form, and in the right image parts, where the location and size of sandbanks inside the tidal channel has changed.
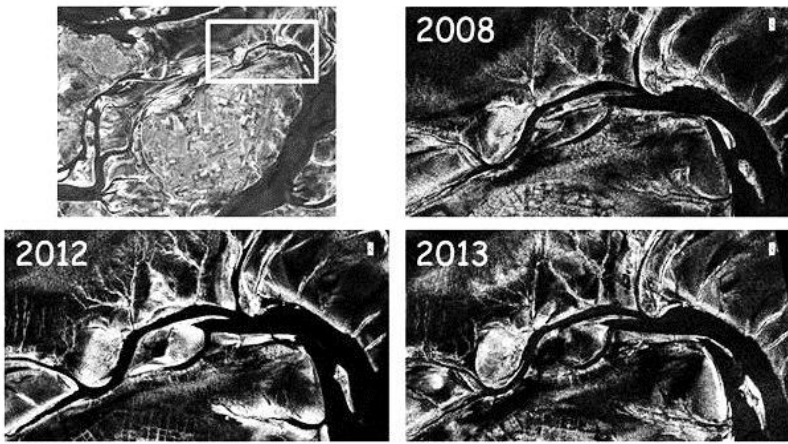

Figure 10. TerraSAR-X images of the "Pellworm" test site (upper left panel; the island is in the image center, the white rectangle indicates the $(4.2 \mathrm{~km} \times 2.3 \mathrm{~km})$ part shown in the other panels). Upper right: July 1, 2008, 17:01 UTC; lower left:

October 28, 2012, 05:50 UTC, lower right: May 7, 2013,

17:01 UTC. All images were acquired within a few minutes around low tide 
The respective temporal coefficients (Eq. 2) are shown in Figure 11 , where the upper panel refers to a comparison of the SAR images of 2008 and 2012 and the lower panel to a comparison of the SAR images of 2008 and 2013. Note that the temporal coefficients were calculated using the calibrated SAR data, whereas all panels in Figure 10 were optimized in terms of the image contrast; therefore, the brightness values are not directly intercomparable.
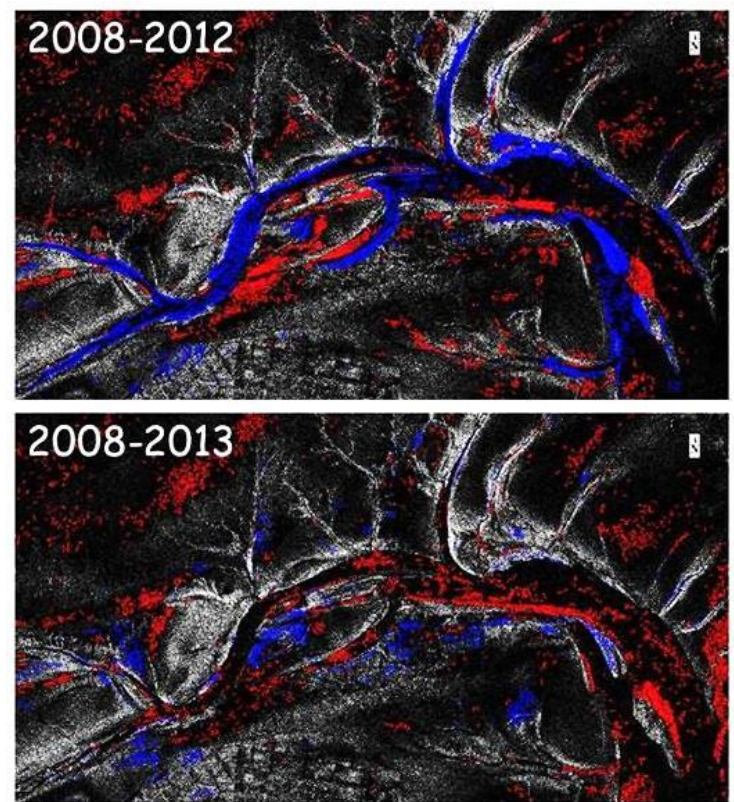

Figure 11. Temporal coefficients derived from the SAR data shown in Figure 10. Red colors denote much higher radar backscatter in the newer image $(T C>0.8)$; blue colors denote much higher radar backscatter in the older image $(T C<-0.8)$

The strong changes detected between 2008 and 2012 (upper panel in Figure 11) along the tidal channel can be attributed to different water levels during the image acquisitions. However, the narrow tidal creek in the lower image center and the sand banks in the tidal channel on the right moved slightly, revealed by blue and red patches at the respective locations in Figure 11 (both panels). In contrast, changes in the radar backscatter from the open flats, in some distance from the tidal creeks and channels, are likely to be due to other factors such as different amounts of remnant water or different soil moisture.

\section{CONCLUSIONS}

Within the national German project SAMOWatt data from multi-satellite SAR images of exposed intertidal flats are being analyzed to improve existing classification systems by including SAR data. We have demonstrated that a systematic analysis of SAR data from exposed intertidal flats, acquired close to low tide, provides valuable information to be used for the routine monitoring of the German Wadden Sea. In particular, the combination of multiple SAR data acquired at different times, from sensors aboard different satellites, or at different polarizations may provide input for existing classification schemes.

Our results based on dual-polarization SAR images are very promising, since they allow for the detection of bivalve beds, particularly when the images were acquired at incidence angles exceeding $40^{\circ}$. We have introduced the polarization coefficient, a dimensionless parameter that can be easily used to generate indicators for bivalve beds, particularly when basic statistical operations (mean and standard deviation) are performed within (running) spatial windows. Others (Choe et al. 2012; Dehouck et al. 2011; Deroin 2012) have already shown that the use of multi-polarization SAR imagery has some additional potential for the monitoring of intertidal flat surfaces using SAR sensors. In particular, the detection of mussel or oyster habitats seems easier when SAR data acquired at multiple polarization combinations are used (Choe et al. 2012). Not only do our results confirm these earlier findings, but they provide an easy method to improve the monitoring of exposed intertidal flats.

We have also shown that multi-temporal SAR data, acquired by single or multiple satellites, can be used to gain information on the Wadden Sea and on its environmental changes. SAR images acquired several years apart can provide information on local morphodynamics, though care has to be taken when the results are interpreted in this respect. In order to provide detailed information on the lateral change of tidal creeks and channels, an exact knowledge of the water level at the time of the image acquisitions is essential. This knowledge, however, can only be provided from numerical models, which in turn are not yet available at resolutions that suffice our requirements of lateral and vertical directions. Nonetheless, multi-temporal SAR image analysis can be an appropriate tool for change detection on intertidal flats, provided that the radar imaging of the same areas does not change significantly, e.g. due to different amounts of remnant water on the open flats, varying soil moisture, or different wind conditions.

The results of our statistical analyses, as presented herein, have already proven as valuable input for an existing classification system, since bivalve beds cause a strong and stable signal in the SAR imagery. We also note, however, that mussels may not be the only cause for a high mean NRCS exceeding the standard deviation. Vegetation on the mainland on the right side of the upper panel in Figure 4 also shows up as bright green areas, and so do extended seegrass meadows during the vegetation period (e.g., in the "Pellworm" test site; not shown herein). Therefore, only a combination of results based on SAR image analyses with those obtained from optical imagery and with a-priori knowledge can provide reliable classification results, as they are needed by the local agencies.

Albeit we cannot infer from the existing data set whether a discrimination between different bivalves (e.g., between blue mussels and oysters, or cockles and oysters) based on SAR imagery is possible, simple statistical measures can help identifying bivalve beds, because of the generally higher surface roughness in those areas. The results of our statistical analyses also show evidence that a discrimination of bivalve beds and shell accumulations is possible. However, we also note that the strength of signatures of mussel beds, and thus the capability of SAR sensors to detect and to classify them, may depend on the seasonal change in coverage by brown algae.

\section{ACKNOWLEDGEMENTS}

The authors are grateful to the colleagues participating in SAMOWatt, who contributed to the results presented herein. Special thanks are due to Kerstin Stelzer and Grit Kirches of Brockmann Consult, who helped with the multi-temporal analysis of the "Norderney" test site, and to Kai Eskildsen and Gabriele Müller of the National Park Agency of the Schleswig Holsteinean Wadden Sea National Park, who provided us with a-priori knowledge about the test sites, thereby helping with the interpretation of the results obtained. SAMOWatt receives 
funding from the German Ministry of Economy (BMWi) under contract 50 EE 0817. Radarsat-2 and TerraSAR-X data were provided by CSA and DLR, respectively, under contract 5077/OCE0994.

\section{REFERENCES}

Brockmann, C., Stelzer, K., 2008. Optical Remote Sensing of Intertidal Flats. In: Remote Sensing of the European Seas. Springer, Heidelberg, pp. 117-128.

Choe, B.H., Kim, D., Hwang, J.H., Oh, Y., Moon, W.M., 2012. Detection of oyster habitat in tidal flats using multi-frequency polarimetric SAR data. Estuar. Coast. Shelf Sci. 97, pp. 28-37.

Dehouck, A., Lafon, V., Baghdadi, N., Roubache, A., Rabaute, T., 2011. Potential of TerraSAR-X Imagery for Mapping Intertidal Coastal Wetlands. In: Proceed. 4th TerraSAR-X Sci. Team Meeting, Oberpfaffenhofen, Germany, DLR Publications, http://terrasar-X.dlr.de/papers_sci_meet_4/oral/LAN237_deho uck.pdf

Deroin, J.P., 2012. Combining ALOS and ERS-2 SAR data for the characterization of intertidal flats. Case study from the Baie des Veys, Normandy, France. Intern. J. Appl. Earth Observ. Geoinf. 18, pp. 183-194.

Diederich, S., Nehls, G., van Beusekom, J.E.E., Reise, K., 2005. Introduced Pacific oysters (Crassostrea gigas) in the northern Wadden Sea: invasion accelerated by warm summers? Helgoland Mar. Res. 59(2), pp. 97-106.

European Commission, 1992. Council Directive 92/43/EEC of 21 May 1992 on the conservation of natural habitats and of wild fauna and flora. Official J. European Communities, L 206, 22.07.1992, pp. 1-66.

European Commission, 2000. Directive 2000/60/EC of the European Parliamant and of the Council of 23 October 2000 establishing a framework for Community action in the field of water policy. Official J. European Communities, L 327, 22.12.2000, pp. 1-72.

European Commission, 2008. Directive 2008/56/EC of the European Parliamant and of the Council of 17 June 2008 establishing a framework for community action in the field of marine environmental policy (Marine Strategy Framework Directive). Official J. European Communities, L 164, 25.6.2008, pp. 19-40.

Gade, M., Kohlus, J., 2011, Archeological Sites on Intertidal Flats in the German Wadden Sea, In: Proceed. 4th TSX Science Team Meeting, Oberpfaffenhofen, Germany, 14-16 February 2011, DLR Publications.

Gade, M., Alpers, W., Melsheimer, C., Tanck, G., 2008. Classification of sediments on exposed tidal flats in the German Bight using multi-frequency radar data. Remote Sens. Environ., 112, pp. 1603-1613.

Gade, M., Melchionna, S., Stelzer, K., Kohlus, J., 2014. MultiFrequency SAR Data Help Improving the Monitoring of Intertidal Flats on the German North Sea Coast. Estuar. Coast. Shelf Sci., doi: 10.1016/j.ecss.2014.01.007.

Kim, D., Moon, W.M., Kim, G., Park, S.E., Lee, H., 2011. Submarine groundwater discharge in tidal flats revealed by space-borne synthetic aperture radar. Remote Sens. Environ. 115 , pp. $793-800$.

Lee, Y.K., Park, J.W., Choi, J.K., Oh, Y., Won, J.S., 2012. Potential uses of TerraSAR-X for mapping herbaceous halophytes over salt marsh and tidal flats. Estuar. Coast. Shelf Sci. 115, pp. 366-376.

Slatton, K.C., Crawford, M.M., Chang, L.D., 2008. Modeling temporal variations in multipolarized radar scattering from intertidal coastal wetlands. ISPRS J. Photogramm. Remote Sens. 63, pp. 559-577.

van der Wal, D., Herman, P.M.J., 2007. Regression-based synergy of optical, shortwave infrared and microwave remote sensing for monitoring the grain-size of intertidal sediments. Remote Sens. Environ. 111, pp. 89-106.

van der Wal, D., Herman, P.M.J., Wielemaker-van den Dool, A., 2005. Characterisation of surface roughness and sediment texture of intertidal flats using ERS SAR imagery. Remote Sens. Environ. 98, pp. 96-109.

Won, J.-S., 2009. Investigation of intertidal zone using TerraSAR-X. In: Proceed. 3rd TerraSAR-X Science Team Meeting, Oberpfaffenhofen, Germany, DLR Publications 